07

\title{
Коротковолновый дифференциальный фотоприемник на основе кремния
}

\author{
(C) В.В. Гаврушко, А.С. Ионов, О.Р. Кадриев, В.А. Ласткин \\ Новгородский государственный университет им. Ярослава Мудрого, \\ 173003 Великий Новгород, Россия \\ e-mail: Valery.Gavrushko@novsu.ru
}

(Поступило в Редакцию 9 февраля 2016 г. В окончательной редакции 18 мая 2016 г.)

Описан фотоприемник на основе кремния, содержащий два одинаковых по площади $n^{+}-p$-фотодиода. Один из фотодиодов имел широкую спектральную характеристику с высокой чувствительностью в ультрафиолетовой области. Чувствительность второго была снижена в коротковолновой части спектра путем создания дополнительных рекомбинационных центров в приповерхностной области методом имплантации ионов As. Исследование спектральной чувствительности дифференциального сигнала, полученного вычитанием фототоков, установило ярко выраженную коротковолновую спектральную характеристику. Границы спектрального диапазона по уровню $\lambda_{0.5}$ находились в пределах $0.27-0.44 \mu \mathrm{m}$. Максимум чувствительности соответствовал $\lambda_{\max }=0.36 \mu \mathrm{m}$. Чувствительность дифференциального канала на этой длине волны достигала $83 \%$ от чувствительности широкодиапазонного канала.

DOI: 10.21883/JTF.2017.02.44144.1752

\section{Введение}

Фотоприемники на основе кремния находят широкое применение в оптоэлектронике. Это связано с возможностью материала эффективно регистрировать оптическое излучение в широком спектральном диапазоне от ультрафиолетового (УФ) до инфракрасного (ИК) излучений, а также с высокоразвитой и низкозатратной технологией кремниевых приборов. Однако при регистрации коротковолнового излучения наличие паразитной чувствительности в ИК и видимой областях часто является нежелательной. Для коррекции спектральной чувствительности обычно используются оптические фильтры $[1,2]$. Использование для глубокого подавления высококачественных внешних фильтров резко увеличивает стоимость приборов и не всегда является эффективным. Кроме того, исследователи отмечают деградацию приборов из-за склонности светофильтров к соляризации [3]. Возможности снижения чувствительности в длинноволновой области за счет формирования встроенного тормозящего поля [4] также дают ограниченный эффект. Интересным является способ формирования спектральной чувствительности фотоприемника за счет вычитания сигналов рядом расположенных чувствительных площадок с различной спектральной характеристикой (дифференциальные фотоприемники). В настоящей работе описан способ получения селективного УФ кремниевого фотоприемника с использованием технологических операций только полупроводникового производства без применения внешних фильтров. В качестве хорошо управляемого способа изменения спектральной характеристики можно применять имплантацию примеси в поверхностный слой, создающую дополнительные центры рекомбинации [5]. Эффективно для этих целей использовать тяжелые ионы, например As [6].

\section{Структура и характеристики фотоприемника}

Структура фотоприемника приведена на рис. 1. Фотоприемник содержал две площадки, спектральная чувствительность которых была идентичной в ИК и видимой областях, но различна для УФ области. Размер приемных площадок для обоих каналов был одинаковым. Один из каналов для обеспечения высокой чувствительности в УФ области, формировался аналогично способу, описанному в работе [7]. Исходным материалом служил кремний $p$-типа марки КДБ-10. Фотодиодная структура создавалась ионным легированием фосфором и его последующей разгонкой для создания $p-n$-перехода с хорошими электрическими характеристиками. Пленки алюминия играли роль оптического экрана, задающего размеры фоточувствительных площадок, а также служили электрическими выводами. С целью снижения связи между каналами размеры экрана в 5-6 раз превышали диффузионную длину неосновных носителей заряда. Для обеспечения омического контакта с $n$-слоем по периферийной области фоточувствительного

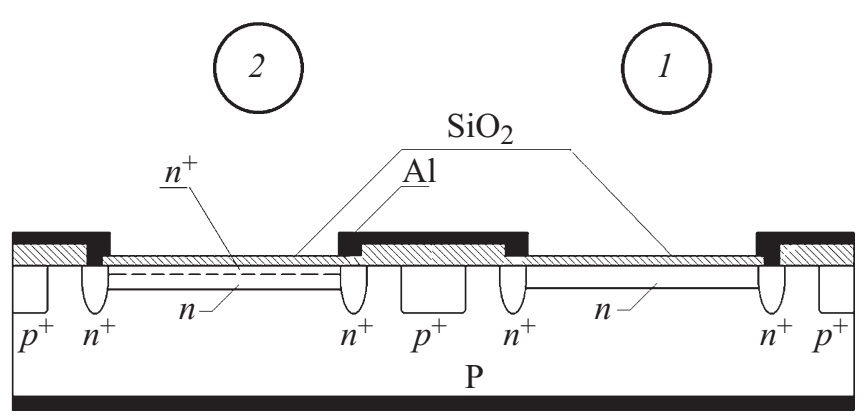

Рис. 1. Структура фотоприемника. 


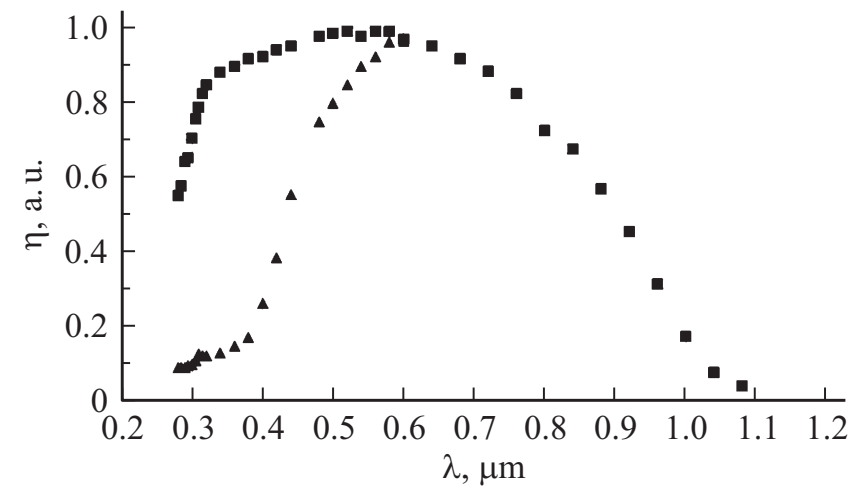

Рис. 2. Квантовая эффективность фотодиодов.

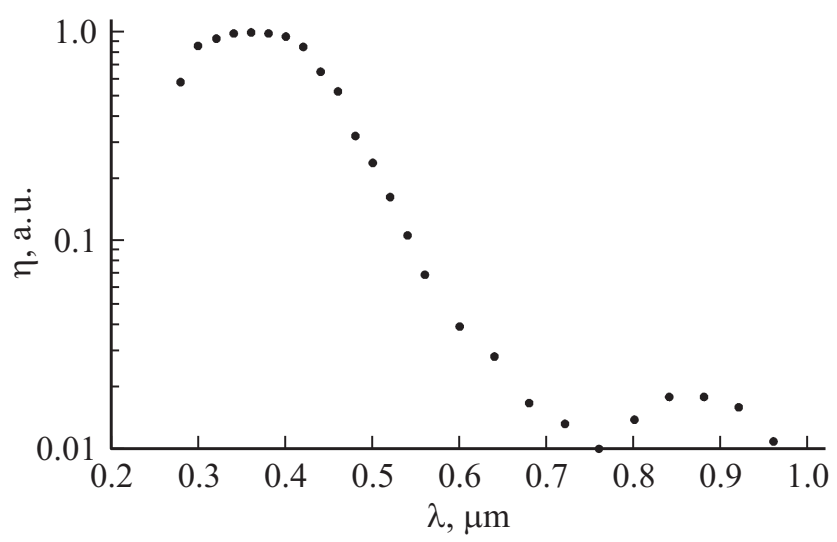

Рис. 3. Квантовая эффективность дифференциального канала.

слоя проводилась подконтактная диффузия фосфора. Диффузионные $p^{+}$-области служили для ограничения каналов инверсии, вносимых зарядом окисла. Второй канал формировался одновременно с первым на той же пластине с использованием общих технологических операций, но с добавлением на заключительной стадии процесса имплантации высокой дозы мышьяка. Такой прием позволил создать в приповерхностной области второго канала дополнительные центры рекомбинации и снизить чувствительность фотодиода в УФ области. Вместе с тем идентичность глубоких слоев обеспечивала близкую спектральную чувствительность в длинноволновой области, где процессы собирания фотоносителей определялись удаленными от поверхности областями. Попытка предсказать количественные физические характеристики такого фотоприемника с помощью математического моделирования, например распределение спектральной чувствительности, вызывает определенные трудности. Это связано с проблемами в количественном определении значений концентрации структурных дефектов, их распределением, степенью ионизации мышьяка в имплантированном слое, параметрами центров рекомбинации. Тем более что эти величины подвержены изменениям в многоступенчатых технологических операциях. В связи с этим для получения достоверных све- дений целесообразно было провести экспериментальное исследование характеристик таких приборов.

На рис. 2 представлена спектральная зависимость квантовой эффективности в относительных единицах для канала 1 и канала 2 (подвергнутого дополнительной имплантации мышьяком с дозой $\left.2000 \mu \mathrm{Q} / \mathrm{cm}^{2}\right)$. Как видно из полученных данных, введение дополнительных рекомбинационных центров позволило на порядок снизить чувствительность второго канала в УФ области. Вместе с тем при смещении к видимой области разница между сигналами в обоих каналах уменьшалась.

На рис. 3 приведена спектральная характеристика на выходе дифференциального усилителя, полученная вычитанием сигналов от каналов 1 и 2. Характеристика имела ярко выраженный максимум в УФ области, около $0.36 \mu \mathrm{m}$. Границы спектрального диапазона по уровню $\lambda_{0.5}$ находились в пределах $0.27-0.44 \mu \mathrm{m}$. Чувствительность дифференциального канала для больших длин волн $(\lambda>0.7 \mu \mathrm{m})$ снижалась почти на два порядка. Одной из причин не полной компенсации сигналов мог служить разброс значений диффузионных длин в базовой области фотодиодов.

Следует отметить достаточно высокую чувствительность дифференциального канала. Так, в максимуме дифференциальный сигнал составил $83 \%$ от сигнала высокочувствительного канала 1 на этой же длине волны.

\section{Заключение}

Описанный в настоящей работе дифференциальный фотоприемник обладал достоинствами, связанными с возможностью получения селективной спектральной характеристики, невысокой стоимостью кремниевой технологии, возможностью в широких пределах изменять размеры фоточувствительных площадок.

Исследование выполнено за счет поддержки Минобрнауки РФ в рамках базовой части госзадания, проект № 1755.

\section{Список литературы}

[1] Патент US № 7196311. H01L 27/15 от 11.08.2005.

[2] Патент BY 8532 U. H01L 27/15 от 30.08.2012.

[3] Гольтберг Ю.А., Царенков Б.В. //ЖТФ. 1996. Т. 66. Вып. 8. C. $195-197$.

[4] Гаврушко В.В, Ионов А.С., Ласткин В.А. // Датчики и системы. 2009. № 6 (121). С. 49-51.

[5] Горшков А.П., Карпович И.А., Павлова Е.Д., Волкова Н.С. ФТП. 2012. Т. 46. Вып. 12. С. $1542-1545$.

[6] Патент RU № 156627. H01L 31/068 от 05.05.2015.

[7] Гаврушко В.В., Ласткин В.А. // Вестник НовГУ. 2014. № 81. C. $53-55$. 